\title{
BP case study: KM team structuration and sense-making (Part II)
}

\author{
C. Gorelick \& K.A. April* \\ Graduate School of Business, University of Cape, \\ Private Bag, Rondebosch 7701, Republic of South Africa \\ aprilkur@gsb.uct.ac.za \& kapril@iafrica.com
}

Received June 2003

\begin{abstract}
This paper summarizes the findings that answered the research questions, stated in Part I of this paper, in the previous edition of SAJBM. The primary research question - In what ways, if any, did the virtual KMT contribute to organizational learning? - was answered: Yes, through the successful completion of performance goals, which included measurable performance as well as learning.
\end{abstract}

\begin{abstract}
The major study findings and conclusions addressed in this paper are: (1) the dynamic interaction among the structural factors, and sense-making factors, human values and emotions plays a central role in effective organizational learning. Strong sense-making factors overcame weak or absent structuring factors, e.g., understanding the various roles internally and externally to BP, and the ability to create a conducive environment for the roles to truly add value, were important aspects which led to success; and, (2) a successful virtual project team, which has executive support and the necessary resources, has both learning- and performing components, and uses collaborative technology and complimentary infrastructures as enablers of that learning.
\end{abstract}

*To whom all correspondence should be addressed.

\section{Introduction}

This paper summarizes the findings that answered the research questions, stated in Part I of this structuration and sense-making paper (published in the previous SAJBM edition). The findings that immediately follow specifically answer, in detail, the subquestions related to the structuring and sense-making variables studied, i.e., information technology (IT), roles, norms, leadership, rewards and recognition and education and development as well as values, language and scripts and schema.

\section{Information technology findings}

Finding 1: The team identified an IT infrastructure as a prerequisite for a virtual team to function. Without the technical infrastructure that supported communication and information sharing, the team could not have functioned.

Finding 2: Collaborative technology enabled organizational learning. No customized collaborative technology tools were used to facilitate the team's knowledge-based work. Although respondents stated that they could not have functioned as a virtual project team without collaborative technology, they were aware that the technology without other structuring and sense-making variables would not have produced effective organizational learning and re-learning.

Finding 3: Once the leaders understood the deep drivers of their social-and learning structure, they moved to support it with suitable sets of information practices, resources and capabilities. All these elements were central components of the information infrastructure, by which we mean not only IT, but also the ways in which key management information was gathered, analyzed, shared and utilized by people. Their challenge was one of developing suitable routines and resources to continuously collect and codify information, and facilitate communications between individuals across the Knowledge Management Team (KMT), as well as the wider community. The main goal of such an information infrastructure was to strengthen and expand the company's social structure of learning (and not vice versa) (Morosini, 2000:247).

\section{Roles findings}

Finding 4: Five separate, but integrated, role categories operated internally within the KMT, externally within $B P$, and externally to $B P$. Internal and external roles were central to the team's existence and success. Within each category there were functional and behavioural roles assigned and assumed that facilitated the team's work as a virtual project team. All the case study participants made assertions relating to the importance of five categories of roles within the team:

\section{Intragroup:}

- $\quad$ Supporting the KMT's socio-emotional issues.

- $\quad$ Supporting the KMT's task issues.

Cross-boundary:

- Supporting client business projects.

- Supporting and participating in the Knowledge Management Community of Practice (KMC). 
- Gaining recognition for BP in the business community as a knowledge management organizational learning leader.

Most participants in the study, and all the team members, were aware that the multiple roles performed by KMT members were key factors in meeting their goals. The roles were often informally defined, and evolved during the life of the team.

\section{Norms findings}

Finding 5: The team perceived meeting (communication) and information storage norms as essential. Although norms evolved over time, having clear and simple rules for communication (e.g., meeting frequency and document storage) were even more critical than if they had been colocated. When asked to describe team processes, everyone mentioned the importance of the meeting every two weeks to 'catch-up,' and the quarterly face-to-face review sessions to accomplish specific team tasks.

Finding 6: The time taken to establish norms differed from one person to the next. Beyond the rules mentioned above, team members reported differing personal levels of need for connection (intimacy needs and bounds). Several found it difficult to meet their own expectations of communication in the virtual context, and recognized how difficult it was to adopt the norms personally. As time went on, the team institutionalized more of the processes successfully.

Finding 7: A policy of minimum norms allowed for the necessary flexibility for learning. It is interesting to note that no policies were identified as critical to the KMT. This was explained as a BP norm of very few mandates, which translates into a minimum number of policies. Policies were limited to corporate safety, legal and ethical issues.

Finding 8: Developing tools and techniques were components of the team goals and performance contract: to develop and implement tools and techniques to support BP in an ongoing learning process. The KMT's knowledge management framework included seven tools and techniques - After Action Reviews (AAR), Connect, Knowledge Assets, Learning Histories, Peer Assists, Retrospects, and VT (PC video conferencing and associated coaching) - that enabled teams to learn before, during, and after a project was complete. Information on these tools was available through KMT publications and the Website. Some KMT members actively facilitated the use of these tools for business projects.

Finding 9: Use of, and people's views regarding the impact on the organization of, the tools varied among members. Team members did not share the same perceptions about how processes like AARs should be implemented. However, all described it as a facilitated group process at the end of an event. A team member explained his view of the AAR as a 'personal learning tool'. Other team members viewed the AAR as a group process. This demonstrates the challenges in transferring learning. Although team members reported AARs as highly successful, they disagreed on the impact such tools had on the organization as a whole, and recognized that people used the tools differently. While many participants were adamant about the value that could be associated with these techniques when they were used, many recognized that the techniques and tools were not always used within the KMT itself and in the broader BP organization. They were aware that the techniques and tools were not yet institutionalized (part of the 'fabric') something we, as researchers, have termed 'patchwork diffusion.'

Finding 10: Lack of time was repeatedly identified as a major barrier to institutionalization of the KMT techniques. Participants articulated time-related challenges of developing processes and procedures that would be implemented and institutionalized. Team members believed that, once people recognized the value to themselves and their team, they would 'find the time'.

Finding 11: The lack of shared norms at the beginning of the team's formation was a barrier. Members stated that defining norms early in a team's life is desirable, but a team also needs time and experience working together, preferably face-to-face, to be effective. Everyone recognized the change in the team's effectiveness once they added shared norms, which they defined as providing 'structure' to the work. When he was asked what he would do differently with a new team, based on his learnings from the KMT experience, the leader responded as follows:
'The thing I would do differently would be to immediately establish some processes and techniques to back up the communication process. I would set up a structure [definitive norms: rules and procedures] realizing it won't be perfect.'

Finding 12: Measurable task-related norms aided learning and performance. The team perceived task-related norms as easier to adhere to than behavioural norms, because taskrelated norms are often measurable. Many team members described norms related to team meetings but recognized there was a lack of norms for virtual communication, sharing non-project-related information and experiences (dialoguing forums). One team member observed that the team itself had difficulty implementing its techniques. The team was disciplined about identifying and documenting their task-related processes. Respondents were aware that they were unusual as a team in having most of their concepts and processes written down - they had a process to create, an ongoing users guide, to share within the team and with others. But this did not include social, interpersonal or organizational network information. Several participants described the need to feel connected to the other team members.

Finding 13: Time-based process norms, and inter-personal relationships, aided performance. Process norms, e.g., meeting times and frequency of communication can be established and will facilitate the team process. The informants recognized that it took time for the team members to be comfortable with themselves and each other, so that they behaved as a collective. There was no consensus on the definition of 'being comfortable', but there was a sense that 'we knew when it had happened'. The 
most significant norm, that all the participants spoke of, was the importance of the face-to-face meetings (Away Days). The leader reflected on his experience of the need for explicit norms and a structure.

'In a virtual team, you need to be very specific, and you actually need to go after some of this stuff which would happen more normally or obviously in a face-to-face situation, which is why, by the way, we had so many Away Days'.

Individual differences were evident when team members discussed their needs for interaction within the team. There was universal awareness that it was more difficult to remain 'connected' with members who were rarely physically together, but the need for 'connection' and frequency varied. Travelling team members found it difficult to stay in touch. Respondents were aware that it was not a technology issue ('you could always use the phone'). At the end of a day participants found it difficult to call or e-mail, for an informal check-in that would have been natural at the end of the day in a co-located environment. The disciplined effort on the part of virtual team members has to be very conscious and purposeful in this regard.

Finding 14: Structure and pre-work contributed to successful face-to-face time. Setting up team procedures was effective according to the informants. All participants mentioned meeting standards: they met every two weeks and always had an agenda, an outside facilitator and meeting notes. Over time a procedure evolved where an individual team member volunteered, or was appointed, to personally contact anyone who was not able to attend a meeting (faceto-face, or via voice or PC video conferencing).

Finding 15: The absence of stakeholder norms made organizational learning (beyond the KMT) difficult. Many informants were aware that norms were required beyond the team and its tasks, and that they had not created an effective process for non-task related information transfer. The need to inform stakeholders (not team members) was evident, and the informal mechanisms of co-located teams were not available.

Finding 16: The scheduling and timing of face-to-face meetings have an impact on the usefulness of the meetings. The need for face-to-face communication at the right times was acknowledged by all the KMT members. This raises issues about trust, and the ability of a project team to function without any face-to-face connections.

\section{Leadership findings}

Finding 18: During the KM initiative the leader was identified as the team 'salesperson' and spokesperson, and was recognized as having a charismatic personality. The importance of the leader himself was a universal theme (from KMT and KMC members). The combination of the leader's position, appointment by a senior executive committee, and personality were key factors in the team's success, particularly at start-up. Participants spoke of the leader's role, but were most emphatic when they described his prototypical characteristics. 'Charismatic' was the most frequently used term. 'Powerful', 'a presence' and 'strong' were other adjectives associated with the leader.

Finding 19: Visibility of the team leader is important to the team's success. Everyone recognized that there was one appointed leader of the team, who gained high visibility within, and outside, BP. All the team members were aware that the KMT's success depended on influence, and that the leader was a critical element in gaining access to business project leaders to raise awareness about knowledge management and the contribution the team could make to a business project.

Finding 20: Personality friction can sometimes deplete individual member's commitment. Some of the same personality traits and actions that contributed to success, were at times seen as detrimental to individuals within the team. The principal descriptors related to leadership overlapped with roles and characteristics attributable to the team leader.

Finding 21: Sharing accountability and responsibility rules that still apply. Making a team responsible and accountable for its own performance obviously has repercussions for the team leader. He, therefore, had to avoid 'knowing what was best' for the team, act in a facilitatory role, and provide the climate for learning opportunities in undiscovered areas in which individuals in the team could thrive - principles which were equally valid and known in the industrial age, but not widely practiced. The leader's perspective was that leadership issues aren't different working virtually... [As a leader you should] provide a framework, then build people's confidence, respect and trust enough to allow them to push against the boundaries and framework that you've created as a leader.

Finding 22: Relationship building, inside and outside of the $K M T$, enables success. Relationship building is a key element in the KMT processes. The leader stated his belief in building on existing relationships with internal and potential external BP clients. He also expressed a strong commitment to reciprocity and intention.

\section{Rewards and recognition findings}

Finding 23: Rewards (essentially financial) was not dominant subjects for team members - but recognition and individual motivation were. Intrinsic rewards were discussed more often than compensation. Individual team members were motivated by a number of expectancy factors (described in Part I): performance-outcome expectancy, internal recognition expectancy, external recognition expectancy, individual-team learning expectancy, teamperformance expectancy, effort-performance expectancy and effort-learning expectancy, interpersonal-performance expectancy, team sustainability expectancy, and personallearning expectancy.

\section{Education and development findings}

Finding 24: No formal training programs were adopted as part of the KMT initiatives. The team acknowledged the importance of training programs but recognized that formal training had not been developed due to lack of time (or 
perhaps priorities). A training program was also not an item in anyone's performance contract.

\section{Values and language findings}

Finding 25: The team was passionately aligned on mission and objectives, but tactics were individual and situational or context-based. The team spoke, and was aligned along, a common language. Cohesion and alignment within the team at the mission- and objectives level was considered a critical success factor. A corollary was the expertise and autonomy of each team member to develop his or her own process based on context. The team was totally aligned on their mission: to embed knowledge management principles and the framework established by the KMT in the BP organization. The overall goal was passionately and emphatically described by many of the team members. Beyond the aligned mission and objectives, team members (particularly the people consulting on business projects) felt autonomous. Some members could be described as sole practitioners (self-driven) doing what needed to be done at any specific moment (and reporting back to the group periodically). This was a preferred operating method for the team members, who seemed to want some structure and support, but autonomy in working on their individual projects. However, team members' personal identities were not significantly relevant during team presentations or when they told a story.

\section{Scripts and schema findings}

Finding 26: KMT deliverables (goals, outcomes) were developed at face-to-face meetings. Participants described face-to-face events as being the time when the team was most successful. An outcome of the face-to-face meetings was often an important team deliverable, e.g., strategy, presentation, project plan, or concrete artifacts that were stored in the Memory and Meaning function of the OLSM. Times that were least successful were when contact and connection were minimal, and lack of communication and leadership were reported.

To summarize, the study found 26 dominant themestwenty-four related to structuring variables and two related to sense-making factors - that supported the KMT's organizational learning. This concludes the section describing respondents' viewpoints of the KMT's contribution to organizational learning. The next section describes the integration of the learning, seen through the lens of the sense-making and structuring media of exchange, with collaborative technology in the virtual KMT.

\section{Overall integrative findings}

There was a duality in the interaction between structure (rational technical processes) and sense-making (human values and emotions) that synthesizes the two, rather than opposing them (dualisms). The KMT contributed to both learning and performance subsystems that represent organizational learning. On the face of it, the KMT interviews focused on structures, the roles people play, tools and techniques developed, and uses of technology. The intense conversation and stories describing the team's successes and difficulties were recurrently social, rather than technical. The focus of team members on embedding the knowledge management concepts in the organization was clear and evident in every conversation.

Finally, collaborative technology in the form of information bases provided structure, but not all information in the databases was knowledge. The transformation of information into knowledge depends on human input, following action. Knowledge Assets as an artifact can be considered a structuring element with a 'how-to' information component. This might include procedures, formats, etc. For information to become knowledge, the human experience (values and emotions) must be added (e.g., describing the action, the feelings and emotions around what happened, including what happened, who was involved, why they were involved, what it felt like with them involved, what could be done better in the future, etc.).

\section{Interpretations and conclusions}

The major thrust of this descriptive case study was to understand if a virtual project team contributed to organizational learning. The study results suggest that the knowledge management team (KMT), a virtual project team contributed to organizational learning at the team and British Petroleum (BP) levels and that collaborative technology played enabling and structural roles. The KMT's contribution to organizational learning was evident as it continually reused available information; processed, interpreted, disseminated and acted on new information; and created new knowledge in the process of meeting the team goals. An unanticipated conclusion was that collaborative technology should be defined and analyzed as one of the structuring variables in the dynamic process of organizational learning, and not considered as a separate construct because of the virtual team context. Conclusions related to the functions, and variables in the OLSM follow the discussion on the performance and learning subsystems.

The overarching study conclusion is that a virtual project team (the KMT) which actively, and purposefully, uses collaborative technology is a team that both learns and performs. The performance and learning subsystems are inextricably, and dynamically, connected. Optimally, the learning and performing subsystems of the OLSM are closely integrated and aligned. Thus, the major study conclusions are:

Conclusion 1: A successful virtual project team, has both learning and performing components that contribute to organizational learning and, actively and purposefully uses collaborative technology.

Conclusion 2: The KMT contributed to organizational learning through knowledge management initiatives such as creating a knowledge management framework that included specific tools and techniques. These conclusions indicate that the performance and learning subsystems can move closer together, with the ultimate goal of integrating learning with performance activities so that the two become an interlocking spiral. In this study, the movement occurred through the processes, procedures and tools the KMT 
developed and defined as knowledge management.

After determining that the team contributed to organizational learning, the study produced two conclusions highlighting the ways in which the team contributed.

Conclusion 3: For the virtual team, length of time (life of the team and project duration) is a significant factor in performance and learning. Conclusion 4: The dynamic interaction (dualities) among the rational technical processes for movement of information throughout the organization (structural factors) and human values/emotions (sense-making factors) played a central role in effective organizational learning at the team and organization levels. Strong sense-making factors overcame weak or absent structuring factors.

\section{Structuring variables contribution to organizational learning}

An overarching conclusion from this study is that the impact, of the structuring variables addressed, depends on individual team members' perceptions and actions, and is also situationally dependent. This supports the findings of Schwandt and Marquardt (1999).

Conclusion 5: An IT infrastructure was a foundation for organizational learning. The KMT took the infrastructure for granted. Conclusion 6: Collaborative technology alone did not support organizational learning. Collaborative technology is an enabler. If All You Do Is Build It They Will Not Come (Gorelick, 1995). This proposition was supported by this study and can be applied to both collaborative technology as a structuring variable and the more generic change process (knowledge management) that was the team's mission. Collaborative technology affects team structures, communication, coordination, and performance. Electronically-supported teams can develop a rich communication structure that is different from (but supplemental to) more traditional communication structures with less hierarchical differentiation, broader participation, and more fluctuating and situational leadership structures (Sessa, Hansen, Prestridge \& Kossler, 1999). The study validates the assumption that collaborative technology can help individuals and teams work together virtually in a qualitatively better way. Figure 1 is a model of the conclusion related to elements that constitute collaborative technologies' contributions to organizational learning through communication, coordination and collaboration.

The study findings emphasize that the processes, that the tools support, are highly dependent on the sense-making variables, including values and language. Several team members explicitly recognized trust as a prerequisite for successful teamwork. Trust is increasingly noted as a success factor for teams and for virtual teams particularly (O’Hara-Devereaux \& Johansen, 1994; Handy, 1995; Lipnack \& Stamps, 1997; Jarvenpaa, Knoll \& Leidner, 1998). Trust, coupled with respect and friendship (terms used by the team leader), is an antecedent to team interactions that include dialogue. Dialogue ('meaning flowing through') is essential for collaboration (April \& Cradock, 2000; Issacs, 1999; Schrage, 1995; Senge, 1990).
Successful trust-building hinges on three components of dialogue, i.e., intention, preparation and mechanics, and includes the mastery of the three essential types of listening in one's toolset: interpretive listening, evaluative listening (both of which were highly developed in the KMT) as well as hermeneutic listening (allowing for themes to emerge, whilst suspending one's judgement).

According to Senge, Kleiner, Roberts, Ross and Smith, (1994:353), dialogue is a 'sustained collective inquiry into everyday experience and what we take for granted'. Being able to engage in people's stories and experience (personal knowledge) is an indicator that we are building trust and a sense of community. People have to have a degree of trust to tell their stories to others, and when they do and people begin to know each others' stories, it creates a sense of connection and belonging, and protective relationships - so necessary for successful collaboration and intra- and extrameaning formation. Without dialogue, team interaction is limited to only communication and coordination, both of which are elements of successful projects. However, dialogue is the differentiator that leads to collaboration, a process of co-creation where two or more people with complementary skills interact to create a shared understanding where none had existed or could have existed on its own (Schrage, 1990). April (1999) sees the process of conversation and dialogue as 'forcing one, in a sense, to make explicit things we could not [or did not] talk about'. Knowing people's stories - their hopes and fears, their expectations and disappointments, their insights and insecurities, their aspirations and avoidances - strengthens the connection, enriches the relationship and generates genuine care, because we get right into people's personal experiences and knowledge - we, as researchers, like to term this both as the 'emotional capital' and 'spiritual capital' available to organizations. People's stories illuminates the rich diversity of their experience (even if, in this case, it has only been in BP), challenges the plausibility of perspectives, and captures the flow of changing realities.

We noticed that there were patterns in the KMT values that guided their conversations and engaged their stories, which, when realized, created positive connections and caring relationships. It was this 'relational practice' (Lewin \& Regine, 1999) that provided continuity for people in times of rapid change and possible, perceived fragmentation.

Everyone on the team suggested meaningful conversation as critical to the team's success. Not unexpectedly, the researchers found that the majority of the communication in the KMC was information sharing or dissemination, and advice. This might be attributable to the logic-based, analytical, engineering culture dominant in BP and might have broader implications for virtual teams, supporting Daft and Lengel's (1986) media richness theory that face-to-face interaction facilitates perception of complex events and invention of innovations. Members of the KMT who were able to use technology disputed this, saying same-time, different-place (PC-VT) communication, combined with other tools, allowed them to have rich interactions. Electronic connectivity, it appears, enabled informal, nonlinear conversations which, unlike agendas in regular meetings, are pathways to unexpected, non-linear results. 


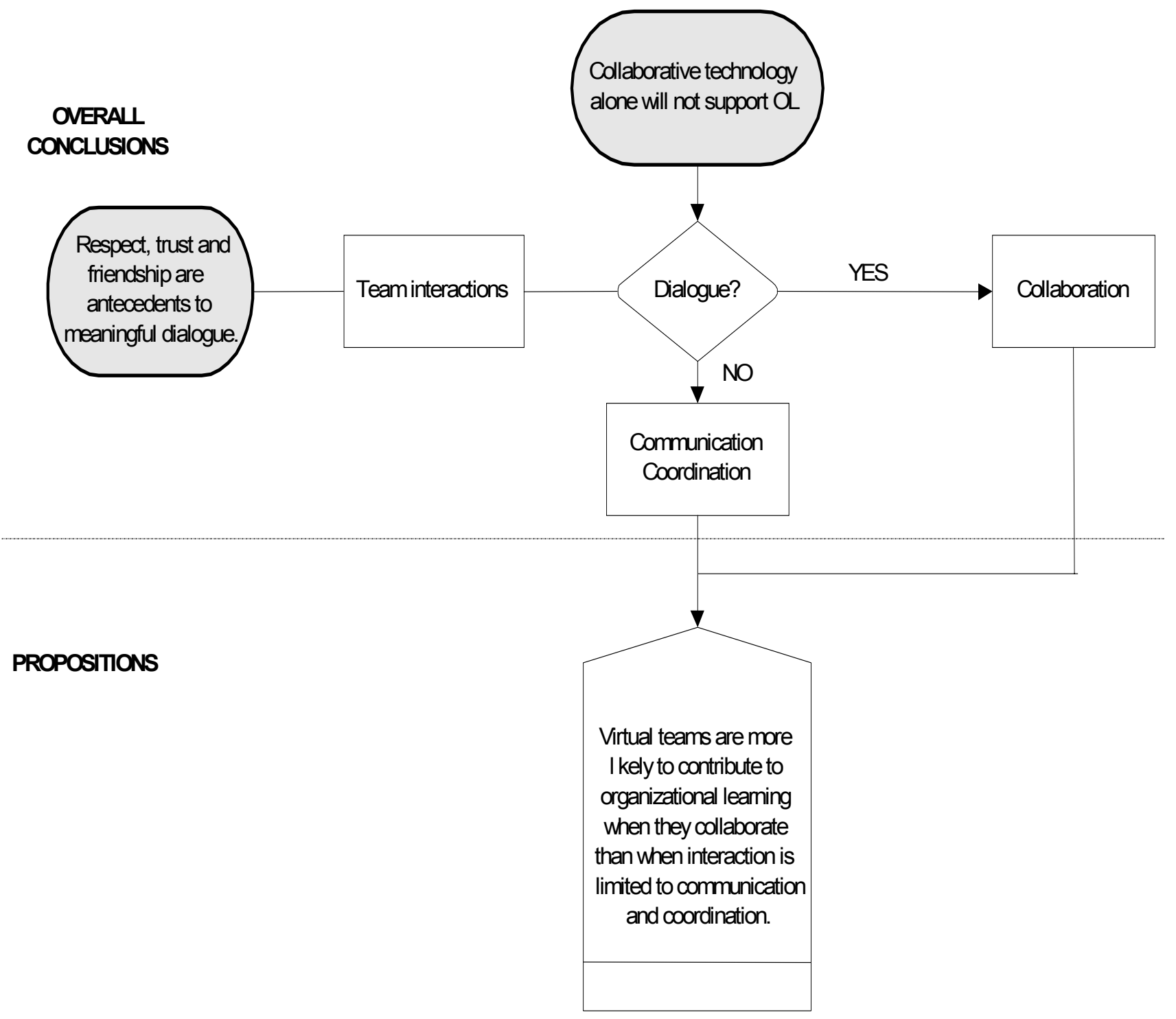

Figure 1: Antecedents of collaboration

The study supports Webber's (1993:xx) position that:

'... conversations are the way knowledge workers discover what they know, share it with their colleagues and in the process create new knowledge for the organization. The panoply of modern information and communication technologies can help knowledge workers in this process. But all depends on the quality of the conversations that such technologies support'.

Conclusion 7: New and different roles were required for the virtual team to contribute to organizational learning. Conclusion 8: Socio-political themes play out to influence the organizational knowledge structure and effectiveness of virtual project teams. The process of developing the organizational knowledge structure is ongoing and continuous. Changes in a company's environment (internal and external) may be perceived in multiple ways by many members, and each may interpret it in different ways. However, when the change begins to affect company performance (positively or negatively), and when it cannot be adequately explained or predicted through the existing knowledge structure, it creates a challenge to that existing knowledge structure and creates an interactive effect among the organizational participants, their roles, their environment and their behaviour (Bandura, 1977; Davis \& Luthans, 1980). Of the structuring variables investigated in the study, role was the factor that received the greatest proportion of discussion within the interviews, and generated the largest number of principal descriptors.

Overall the consistent pattern described by participants in this study was that both individual and collective roles are more flexible and fluid in virtual teams. Duarte and Synder (1999:121) state that the ability to balance coordination and collaboration, with autonomy, is a more complex challenge for virtual teams than for co-located teams. 'Virtual team members may be tempted to work independently because coordination and collaboration are more difficult in a virtual situation'. Hence, the degree of consensus about goals, and about the means of achieving them, influences the effectiveness of a virtual team.

Also, within the wider BP organization, socio-political themes, such as credibility and power, added to the 
challenge for the way in which these team members were working. Political processes are evoked when different coalitions (e.g., managers, analysts and support staff) within a firm, who hold alternative schemas, advocate their own positions through such mechanisms as task forces, project teams and special reports (Lyles \& Schwenk, 1997; Prahalad \& Bettis, 1986; Lord \& Foti, 1986). These different coalitions attempt to influence others, and to gain the agreement of others, about the coalition's interpretation of events (Lyles \& Mitroff, 1980). Changes in the organizational knowledge structure occur as a result of the impact of the interpretation of environmental events, results of past organizational actions, the influence of the key decision-makers and the advocacy position of coalitions within the organization.

Conclusion 8: Explicit norms about technology use, and face-to-face contact, were required for organizational learning at the team and organizational level. A study conclusion was the importance of norms to guide the work of the team. Team literature identifies the need for norms, defined as policies, procedures, and rules, for all teams. Explicit norms relating to internal team processes, as well as technology use, are even more important to virtual teams than to co-located teams (Lipnack \& Stamps, 1997; Haywood, 1998; Duarte \& Snyder, 1999), a viewpoint supported by the study findings. For the KMT, having explicit norms was a critical element of the team's interaction, and the framework and tools they developed to accomplish their mission. The major procedure adopted and propagated by the KMT was for learning to systematically be done before, during, and after a project. In conjunction with this procedure, several tools and techniques were developed. The tools can be mapped to the elements of the learning subsystem in the Schwandt OLSM (Figure 2).

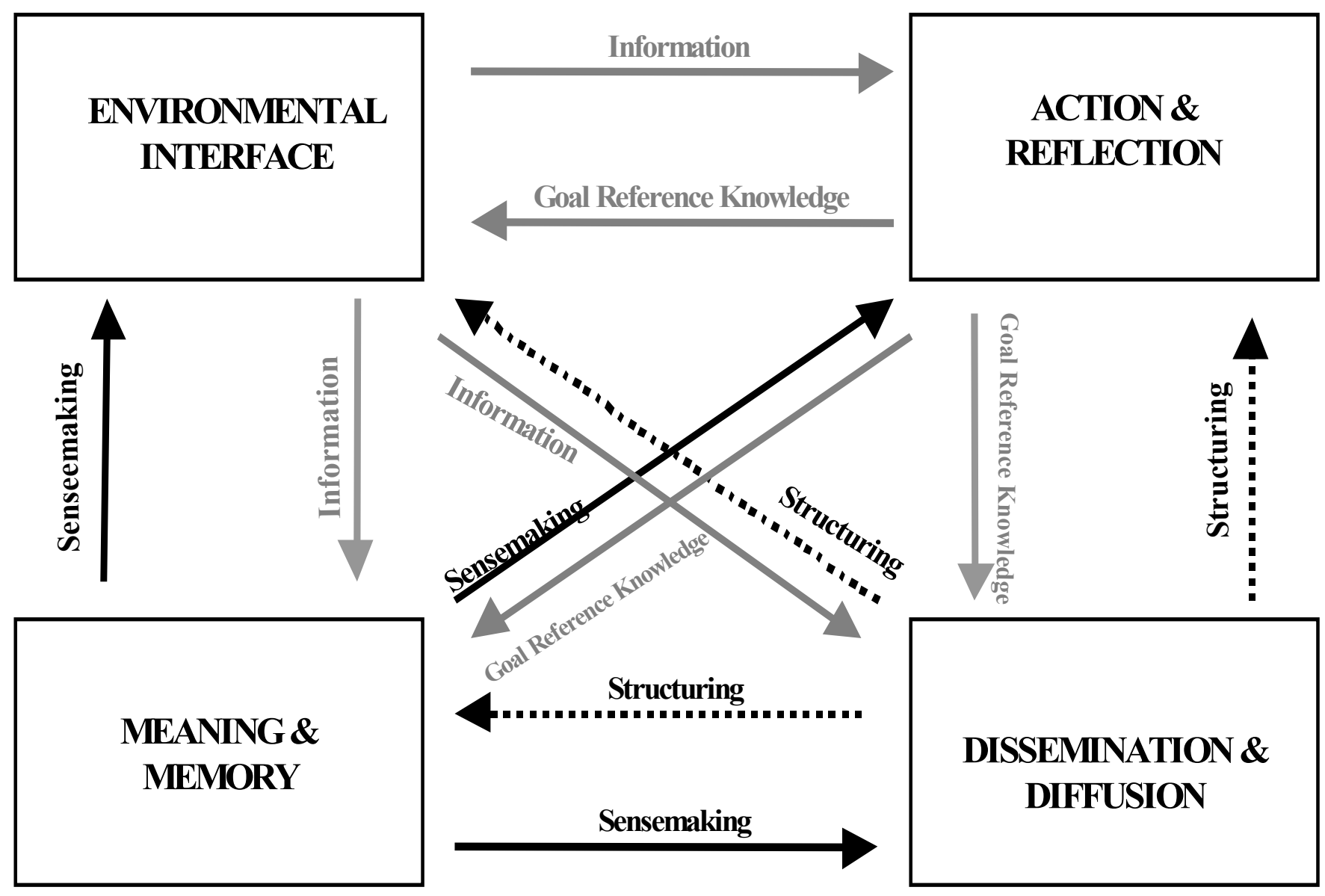

Figure 2: Media of interchange in Schwandt's learning subsystems

Conclusion 11: Formal actions related to education and developments were not taken but the KMT recognized them as important activities.

\section{Contribution of sense-making variables to organizational learning}

Conclusion 12: Enthusiasm, passion, and alignment (or cohesiveness) were critical for organizational learning. 
Organizational learning, structuring, and sensemaking: model and assessment

Schwandt's (1994) model is based on Parsons General Theory of Action, which states that the action system of an organization includes individual, group, team (italics added) and organizational actions. For analysis, the theory considers performance and learning as two independent subsystems. The two are dependent on each other and interdependent; working together, they allow the organization to change and adapt to its environment. In addition, each subsystem includes functions represented by 'black boxes'. There is, however, no methodology to analyze the subsystems of actions as yet. Schwandt suggests that we use the interchange processes through which the subsystems relate, to analyze the interrelationship of the action subsystems (Schwandt, Casey, \& Gorman, 1998:12-13). By making use of this interchange media concept, we were provided with a method to symbolically represent the result of each of the subsystem functions.

The complexity of the combination of structuring and sensemaking variables operating in this study supports Schwandt's (1994) premise that organizational learning is a process manifested in patterns of actions and attributes of changing social systems, rather than causal relationships between isolated variables. There is an underlying assumption in the model, and supported by our study, that a change in one variable will probably result in change in one, or more, of the other variables. Furthermore changes in individual variables may result in changes in one, or both, of the subsystems (Giddens, 1979).

Assessing the extent to which the variables, that emerged in our study, affected the learning subsystem was beyond the scope of our study. The study's findings led to Figure 3. It uses the OLSM model to represent BP's organizational learning at the individual, team, business project, and organizational levels. The central KMT box is largest only for explanatory purposes. The solid rectangle has three subsystems represented, because of the dual objectives and three roles within the team (internal social-emotional, internal task, and external- business projects). The learning system applies to the entire team. The first performance subsystem represents the measurable performance of the KMT. The last section of the model represents BP as an aggregate organization (more often thasn not, not necessarily operating according to organizational chart demarcations). The model has lines from each of the performance subsystems at the individual, KMT and business project level into the relevant organizational learning subsystem.

\section{Individuals \\ Central Knowledge Management Team}
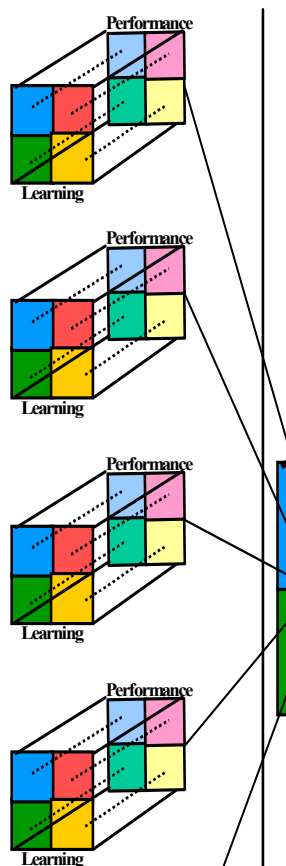

earning

\section{Business Projects British Petroleum}

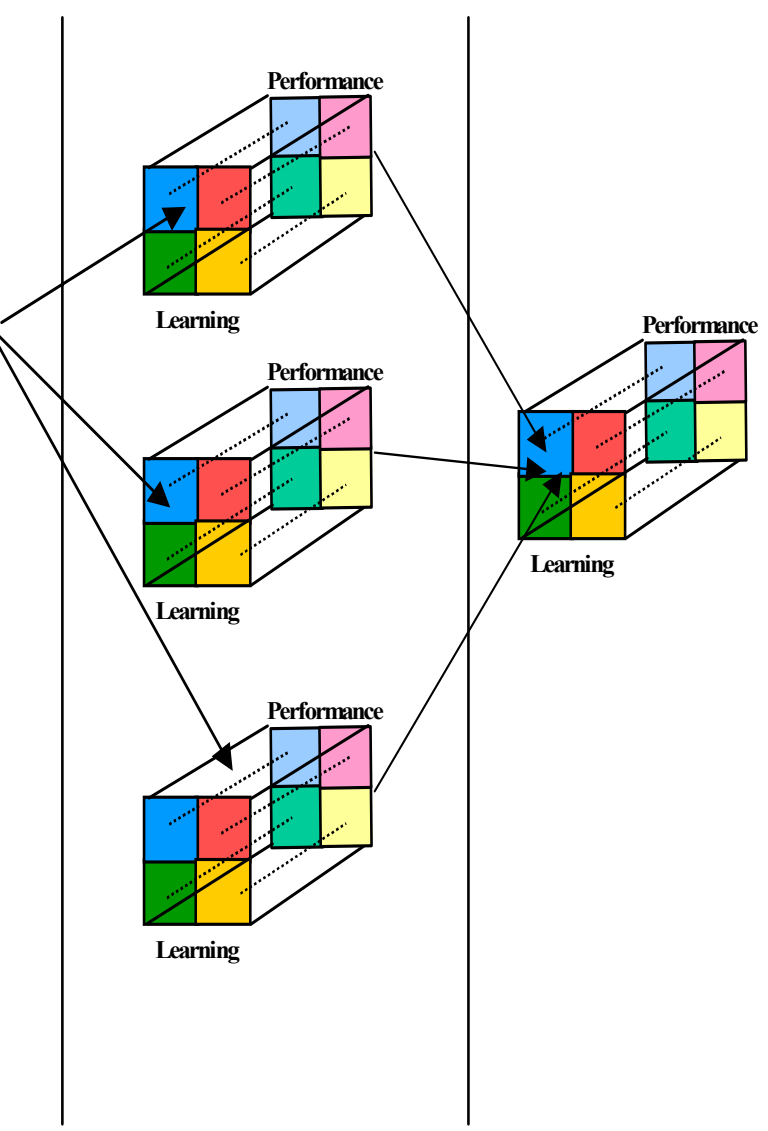

Figure 3: Performance through learning at four levels 
This study used Schwandt's model for analysis of the BP KMT. The researchers propose extending the model. In this version, the two subsystems are integrated to the extent that they cannot be separated. Learning will occur continuously in the process of performing. This supports the KMT's overarching objective to institutionalize performance through learning. When the institutionalization is complete and the two subsystems are aligned, organizational learning will be an integral or core function within business units, much the same way as accounting, IT, human resources and others, have become in many organizations. Organizational learning might no longer be an intervention or tool for organizational change, but will be part of ongoing business processes. In order for this to happen, the structuring and sense-making must be purposefully addressed.

\section{References}

April, K. A. 1999. 'Leading through communication, conversation and dialogue,' Leadership \& Organization Development Journal, 20(5): 231-241.

April, K. \& Cradock, J. 2000. e or b e@te: e-Business redefining the corporate landscape in South Africa. Durbam: Butterworths.

Bandura, A. 1977. Social learning theory. Englewood Cliffs, N.J: Prentice-Hall.

Daft, R. \& Lengel, R. L. 1986. 'Organizational information requirements, media richness and structural design,' Management Science, 32(5):554.

Davis, T.R. \& Luthans, F. 1980. 'A social learning approach to organizational behavior,' Academy of Management Review, 9(2): 284-295.

Duarte, D. L. \& Snyder, N. T. 1999. Mastering virtual teams: Strategies, tools, and techniques that succeed. San Francisco: Jossey-Bass.

Giddens, A. 1979. Central problems in social theory: Action, structure and contradiction in social analysis. Berkeley, CA: University of California Press.

Gorelick, C. K. 1995. 'Groupware implementation: A field study of the use of Lotus Notes by one team in a management consulting firm'. Unpublished paper.

Handy, C. 1995. 'Trust and the virtual organization,' Harvard Business Review, May/June, 73(3): 40-48.

Haywood, M. 1998. Managing virtual teams: Practical techniques for high-technology project Manager. Boston: Artech House.

Isaacs, W. 1999. Dialogue and the art of thinking together: A pioneering approach to communication in business and in life. New York: Doubleday.

Jarvenpaa, L., Knoll, K., \& Leidner, D. E. 1998. 'Is anybody out there? Antecedents of trust in global virtual teams,' Journal of Management Information Systems 2 14(4).

Lewin, R. \& Regine, B. 1999. The soul at work : Unleashing the power of complexity science for business success. London: Orion Publishing Group Ltd.

Lipnack, J. \& Stamps, J. 1997. Virtual teams: Reaching across space, time, and organizations with technology. New York: John Wiley \& Sons.

Lord, R.G. \& Foti, R.J. 1986. 'Schema theories, information processing and organizational Behavior.' In Sims, H.P. Jr., Gioia, D.A. \& Associates. The thinking organization. San Francisco: Jossey-Bass, pp. 20-48.

Lyles, M. A. \& Mitroff, J. I. 1980. 'Organizational problem formulation: An empirical study,'Administrative Science Quarterly, 25: 102-119.

Lyles, M.A. \& Schwenk, C.R. 1997. 'Top management, strategy and organizational knowledge structures.' In Prusak, L. (Ed.). Knowledge in organizations. Newton, MA: Butterwoth-Heinemann, pp. 51-71.

Morosini, P. 2000. 'Open company values: Transforming information into knowledge-based Advantages.' In Marchand, D.A. (Ed.). Competing with information : A manager's guide to creating business value with information content. Chichester: John Wiley \& Sons Ltd., pp. 243-262.

O’Hara-Devereaux, M. \& Johansen, R. 1994. Globalwork: Bridging distance, culture, and Time. San Francisco: JosseyBass.

Prahalad, C.K. \& Bettis, R.A. 1986. 'The dominant logic: A new linkage diversity and performance,' Strategic Management Journal, 7(6): 485-501.

Schrage, M. 1990. Shared minds: The new technologies of collaboration. New York: Random House.

Schrage, M. 1995. No more teams! Mastering the dynamics of creative collaboration. New York: Doubleday.

Schwandt, D. R. 1994. 'Organizational learning as a dynamic sociological construct: Theory and research.' Paper presented at the International Systems Dynamics (ISD) Conference, University of Scotland.

Schwandt, D. R., Casey, A. \& Gorman, M. 1998. 'Dynamic role of collective memory in knowledge systems: A human action theory perspective'. Paper presented at the Conference on Organizational Learning: Moving from Theory to Research, George Washington University, March 22-23.

Schwandt, D. R. \& Marquardt, M. J. 1999. Organizational learning: From world-class theories to global best practices. Boca Raton, FL: St. Lucie Press.

Senge, P. M. 1990. The fifth discipline: The art and practice 
of the learning organization. New York: Doubleday.

Senge, P., Kleiner, A., Roberts, C., Ross, R. \& Smith, B. 1994. The fifth discipline fieldbook: Strategies and tools for building a learning organization. New York: Doubleday.

Sessa, V., Hansen, M., Prestridge, S. \& Kossler, M. 1999. Geographically dispersed teams, an annotated bibliography. Greensboro, NC: Center for Creative Leadership.

Webber A.M. 1993. 'What's so new about the new economy?' Harvard Business Review, Jan/Feb, 71(1): 2442 . 